E3 Journal of Business Management and Economics Vol. 7(2). pp. 044-049 August, 2016

Available online http://www.e3journals.org

ISSN 2141-7482 @ E3 Journals 2016

DOI : http://dx.doi.org/10.18685/EJBME(7)2 EJBME-15-022

Full Length Research Paper

\title{
The impact of the treating customers fairly Legislation on the short-term insurance industry: Santam claims specific
}

\author{
Hein Visser ${ }^{1}$ and Gerhard van Wyk ${ }^{1 *}$ \\ ${ }^{1}$ Milpark Business School, P.O Box 5404, Selby, Johannesburg 2006
}

Accepted 7 April, 2016

\begin{abstract}
Business in general would agree that to treat customers fairly should be the cornerstone of the corporate strategy. According to Taylor (2012) "......customers are seen as the greatest asset after employees for an organisation". The implementation of new legislation forces companies to work according to the new legislation. The aim of this research is to investigate the extent to which staff in the company understand the "treating customers fairly" legislation, determine if the legislation will be part of the culture of the company or will it purely be seen as legislation that the company needs to adhere to and identify possible gaps in the interpretation of the outcomes-based legislation. This legislation should be an integral part of the value, culture and strategy of the company in order to truly have an impact on the customer (Feasibility, 2010:8-10). If the company does not embrace this as part of its strategy and the treating customers fairly principles do not become part of the culture, the client will not experience the true benefit that was intended by the legislation.
\end{abstract}

Keywords: Treating Customers Fairly, fairness, financial services, financial institutions, legislation, service and after sales service, company culture.

\section{INTRODUCTION}

The Treating Customers Fairly Act took effect on 1 January 2014. The Act is an outcomes-based regulatory approach that seeks to ensure that specific, clearly articulated fairness outcomes for financial services consumers are demonstrably delivered by financial institutions. The Financial Services Board (FSB) has published a discussion document with the intention of obtaining views from industry, with a view to refining what is meant by treating customers fairly. The aim is not necessarily to rework the initial discussion document published by the FSB (FSB, 2010), but to stimulate comment and debate. It is intended that written submissions be made on the concepts set out in the document and that a workshop be convened to discuss the comments. The process should lead to a further

${ }^{*}$ Corresponding Author email: Gerhard.vanWyk@icloud.com; Tel: 0714819956 document which will set out the FSB's Treating Customers Fairly (TCF) vision and programme for the next stages.

It is evident that a gap was identified in current insurance legislation, therefore the need for the Treating Customers Fairly Act. If all the information set out in the Act is taken into account, it still remains a framework with no clear indication or set of parameters on what is fair and how fairness will be measured. The aim of the paper is to assist in the understanding of the "treating customers fairly" legislation, if the legislation will be part of the culture of the company and identify possible gaps in the interpretation of the outcomes-based legislation

\section{The financial services act}

The Act was published in 2002 and the opening statement of the acts states: "To regulate the rendering of 
certain financial advisory and intermediary service to clients; to repeal or amend certain laws; and to provide for matters incidental thereto" (RSA, 2002). The South African Financial Services Act now stipulates under Section 8 that any person who offers financial advice or acts as a financial services provider may not do so unless $\mathrm{s} / \mathrm{he}$ is registered and has a licence (RSA, 2002). The aim of the Act was therefore that the legislation implemented must put the fair treatment of the customer at the heart of the business as discussed under the Financial Services Act.

Many of the principles from TCF have been adapted from the UK where TCF was implemented before South Africa. Although the implementation of TCF in the UK took 12 years, South Africa wanted to implement the legislation in less than four years, but nevertheless copied the UK TCF model (Bowman, 2012:1-2). In South Africa these principles were accepted by the FSB and there were also point's added (Jackson, 2011). The added points related directly to the benefit of the client and these included:

Consumers need to be confident that they are dealing with institutions that see the principle of treating customers fairly as the cornerstone of their business. Products and services marketed and sold in the retail sector are designed to meet the standards and expectations of the consumers. All advice is suitable and takes account of the consumer's circumstances. Consumers are informed throughout the process in clear and understandable language.

In South Africa the regulators have set out principles and rules by which companies should operate, such as the Financial Services Act. While the UK TCF programme was seen as a principle-based approach, the FSB made it clear from the outset that the desired outcome for South Africa was an outcomes-based approach.

\section{The role of the Financial Services Board(FSB)}

The FSB is a statutory body established by the Financial Service Board Act of 1990, with the objective of promoting and maintaining a sound financial investment environment in South Africa. The mission of the body is to:

- Ensure fair treatment of consumers of financial services and products

- Ensure financial soundness of financial institutions

- Ensure systemic stability of financial industries

- Ensure integrity of financial markets and institutions
The FSB functions in close liaison with the Minister of Finance, but the board is not funded by government and therefore acts independently. Section three of the FSB Act stipulates the function of the board FSB (2014) and entails supervising the non-banking financial institutions and advising the Minister of Finance. The specific functions are:

- To supervise and enforce compliance with the laws regulating financial institutions and the provision of financial services,

- To advise the Minister on matters concerning financial institutions and financial services, either on its own accord or at the request of the Minister; and

- To promote programmes and initiatives by the financial institutions and bodies representing the financial services industry to inform and educate users and potential users of financial products and services (FSB, 2014).

Section 10(3) and section 10A of the Act provides for the establishment of an enforcing committee to be responsible for enforcing compliance with the laws regulating financial institutions and the provision of financial services (RSA, 2002). The TCF programme is thus well within the mandate of the FSB.

The impact and implementation of the TCF Act will be an addendum to the Short-term Insurance Act (Act 53 of 1998). The statutory FAIS Ombudsman and the Pension Fund Adjudicator, as well as the voluntary industry ombudsmen all have a role to play in ensuring ultimate fairness to consumers.

\section{Approaches to treating customers fairly}

The FSB wants to encourage firms to treat customers fairly without relying on too many rules (outcomes-based instead of rule-based) and in particular wishes to avoid laying down a huge raft of new rules. Its approach is to focus on the six outcomes of the TCF programme see Table 1.

British experience in the financial services industry highlighted some key elements of the debate on how regulators can best ensure that customers are treated fairly. In the UK, the movement towards an explicit TCF policy emerged early in the decade with the FSA arguing in favour of a principles-based approach to regulation (Hawkins, 2010). Movement towards a principle-based approach was seen as a movement away from a rulesbased approach. It has been argued that the debate about rules and principles appears in various guises in different disciplines (FSB TCF Discussion Paper, 2009). In order to facilitate the successful implementation of a 
Table 1: The six TCF fairness outcomes

\begin{tabular}{|l|l|}
\hline Outcome 1 & $\begin{array}{l}\text { Consumers can be confident that they are dealing with firms where the fair treatment of customers is } \\
\text { central to the corporate culture. }\end{array}$ \\
\hline Outcome 2 & $\begin{array}{l}\text { Products and services marketed and sold in the retail market are designed to meet the needs of } \\
\text { identified consumer groups and are targeted accordingly. }\end{array}$ \\
\hline Outcome 3 & $\begin{array}{l}\text { Consumers are provided with clear information and are kept appropriately informed before, during and } \\
\text { after the time of contracting. }\end{array}$ \\
\hline Outcome 4 & Where consumers receive advice, the advice is suitable and takes account of their circumstances. \\
\hline Outcome 5 & $\begin{array}{l}\text { Consumers are provided with products that perform as firms have led them to expect, and the } \\
\text { associated service is both of an acceptable standard and what they have been led to expect. }\end{array}$ \\
\hline Outcome 6 & $\begin{array}{l}\text { Consumers do not face unreasonable post-sale barriers to changing product, switching provider, } \\
\text { submitting a claim or making a complaint. }\end{array}$ \\
\hline
\end{tabular}

Source: Available online from - https://www.fsb.co.za/feedback/pages/tcfhome.aspx [Accessed:28-08-2014]

TCF programme in South Africa, the FSB intends to approach the matter holistically. The following elements need to be considered:

- Providing clarity concerning regulatory expectations

- Providing clear guidance on what is expected by regulators is essential for the TCF framework to succeed.

Firms prefer a system which contains rules of which they are certain. To establish a common understanding between regulators and firms may therefore be challenging. "Firms appear to want explicit guidance on the rules of the game, they want to know what fairness means in terms of their usual business activities" (Hawkins, 2010).

Over and above any legislative or regulatory changes, the TCF programme will involve engagements with the industry, so that guidance notes and tools become useful mechanisms to encourage the programme. A simple example would incorporate:

- Setting out expectations in the form of guidance notes and case studies.

- Involving industry bodies and other experts in helping to disseminate expectations and review the guidance notes.

- Testing that the firms in the industry have an understanding of the concepts similar to their understanding of the FSB.

- Revising guidance notes and case studies in the light of the testing process (FSB, 2010).

- Putting pro-active and intensive supervision in place

In adopting the TCF programme, the FSB is conscious that its supervision will need to become both more proactive and intensive. In recent years, the FSB has been considering adopting a conduct risk approach to market and supervision. This will support to the implementation of the TCF programme. Conduct risk supervision will allow pro-active identification of risks leading to consumer detriment by placing firm behaviour in a broader socioeconomic framework as well as in an industry-wide context. Moreover, the conduct risk approach will provide the point of entry for intensive supervision of firms' business models and culture as well as product strategy, new development and sales (TCF Institute South Africa, 2012).

Ensuring appropriate incentives are in place: The experience of the FSA in the UK suggests that the FSB will require a full range of methods to encourage compliance with the TCF programme (Financial Services Board, 2009). For the TCF programme to work, firms must be aware that the FSB will test their implementation of the programme.

Encouraging consumer responsibility: In South Africa, educational programmes will need to be enhanced so that the consumer is also increasingly aware of his or her need to behave responsibly, and ask about and understand any contractual agreement that they enter into. Creating awareness of call centre facilities or hotlines that can deal with consumer queries will contribute towards a more efficient regulatory system.

Facilitating ultimate fairness by working with the ombudsmen: It is important to consider the role of both the statutory and voluntary ombudsmen and adjudicators in creating the possibility of ultimate fairness. The FSB will need to work in cooperation with the ombudsmen, statutory as well as voluntary, that exists in South Africa and may need to enhance channels of communication.

The way forward: Each of these key elements discussed above is interrelated and its success is dependent on the other elements. Failure to implement any one of these is likely to impact the success of the others. According to 
Exceed Consulting (2008) there are five key elements for successful consulting; upper management support, operational leadership, testing, training and metrics.

\section{Objectives of the study}

The objectives of the study is to explore the level of compliance by companies to the new treating customers fairly legalisation with specific focus on Santam claims processes and procedures. In the larger study objectives were grouped under the following categories: 1) demographics 2) the extent to which staff in the company understand the "treating customers fairly" legislation, 3) determine if the legislation will be part of the culture of the company or will be purely seen as legislation that the company needs to adhere to, 4) identify possible gaps in the interpretation of the outcomes-based legislation. For the purpose of this study, selected variables from all categories are dealt with.

\section{RESEARCH METHODOLOGY}

The researcher will gather data in the form of surveys to determine the impact that the new legislation will have on the claims process. A quantitative research method with closed-ended questions was used. Little information is available on the subject and the research wanted to test the theory available against the practice. According to Sage (2001:1) qualitative research methods have the advantage of consumer (in this case employees') behaviour which provides insight into emotions and motivations. The researcher merely wants to establish the understanding and impact of the legislation on the claims process.

\section{The sample framework}

In order to have the most accurate data, the entire Santam's claims department had to completed questionnaires on the topic. It is, however, not practically possible. Thus sampling were used. In order to have validity, the researcher has chosen two groups, one in Cape Town and another group in Gauteng. This will rule out any difference in geographical location as the two biggest departments are in these two cities. The sample population was limited to the staff within the claims departments. The survey medium that was used was Surveymonkey and all staff within the sampling frame was invited to take part in the survey. The claims departments consist of close to 450 staff members. That not only includes the assessors, but also supporting areas within the claims departments. In order to give an accurate reflection, 180 respondents had to complete and submit the survey. Sampling methods or techniques can be divided into two types, probability or representative sampling and non-probability or judgemental sampling (Patton, 2002). This research made use of nonprobability sampling, more specifically self-selecting sampling. According to Green (2010) data collection tools are helpful because they provide details of the environment. Surveys were used to gather data. The surveys were done anonymously, but participants were divided into groups to make it possible to discuss the results of a specific group with certain selected individuals. A quantitative research method with closed ended questions was used. The results of the survey were unpacked by testing the various or applicable questions against the hypothesis as well as the research question. These results were further analysed by discussing the responses given by a specific group. Based on the research done by McMillan and Schumacher (2006) care was taken in every step of the research process that influence the trustworthiness and validity of the survey. The results of the surveys conducted in Santam's claims department were discussed.

\section{Demographics}

The respondents in the study were not requested to provide race, age or gender. The survey was conducted within the claims environment within the company on a national basis. The roles within the environment are the same, with the only difference being the size of the departments in the different regions. The survey was for different users as the result must be per company and not per role. Options were given to respondents according to their roles. A total number of 230 surveys were completed and analysed. A summary of the research findings revealed the following:

\section{Understanding the legislation}

The result reflected that close to $80 \%$ of staff confirmed that they received the training. The researcher has confirmed with the company that the pass rate was $85 \%$ and that the system would not allow staff to proceed if they did not pass. Company results also indicated that at the time of the training (November 2013) 95\% of the staff completed the training (Internal confirmation from Human Resources).

Legislative impact on staff: The result indicated that since implementation in 2014, $67 \%$ of the staff has seen changes in the company as a result of the legislation. The majority of staff members also confirmed a cultural048 change with in the organisation to being more customer focus. 
Treating Customers Fairly: The majority of respondent $65,4 \%$ agree that the new legislation will play a substantial role going forward and that the company will change due to the implementation process. $93 \%$ of the respondents confirm that leaders within the company constantly talk about the legislation and that the implementation is taken very seriously. Santam recognises that complying with the FSB's proposed requirements on TCF will be a regulatory obligation and is therefore mandatory.

Fairness to the client: Some $53 \%$ of the respondents either indicating that the legislation will override their current insurance contract or they are not sure. The aim of the legislation is however not to override the contract, but to make sure that the service the client receives is fair and that the company abides by the six principles of the legislation. $81 \%$ of respondents indicated that they first think of compliance to the legislation before processing a customer's claim.

Prescribed method to follow when handling complaints: Only $64 \%$ of the respondents indicated the they knew how to handle complaints within the prescribed method to be followed.

Measurement and reward: Up to $60 \%$ of the respondents indicated that TCF is part of the performance appraisal process. It is then clear that the company reward staff if they embrace the culture of TCF.

\section{Conclusion}

The aim of this paper is to investigate the level of compliance by companies to the new treating customers fairly legalisation with specific focus on Santam 's claims processes and procedures. Both from a company perspective as well as from the surveys it is clear that the company has a heighted level of compliance with the new treating customers fairly legalisation. Santam has also succeeded with its training and has put measures in place to make sure that employees are trained and understand the impact of the legislation on their roles. Training will, however, not be a once-off exercise and the results have already shown a number of staff members who cannot remember or have not completed the training. The need for constant retraining and follow-up training were identified to make sure that all staff adhere to the new legislation.

\section{Recommendations}

Implementing the following recommendations derived from the research could assist further compliance with the new Treating Customers Fairly legislation as it would be a risk to assume all staff is living the strategy intended by the company:

The legislation needs to become part of the culture of the company and needs to be challenged and tested over and over. It is furthermore important that this implementation is not silo based, as the impact is on a company level and not on a departmental level.

Companies implementing TCF strategies need to establish a TCF working committee, making sure that they receive input from all departments and the outcome of all complaints or queries where clients feel that they have been treated unfairly. These recommendations or outcomes need to be implemented in policy wording and contracts to make sure that the clients are informed upfront and are aware of policy rules and conditions.

The risk remains that staff will be confronted with the legislation or by clients claiming that they have been treated unfairly, but it is important that the legislation does not change the contract or outcome, but rather checks to see if the process that was followed (from design to implementation to after-sales service) was fair.

The bigger risk is for the intermediary companies. Since the broker serviced the client and all advice to the client was from the broker, claims staff did not need to be FIAS compliant, as they did not supply advice, they merely supplied a function. With the new legislation the role will now change and claims staff will advise clients on precautions as well as steps to minimise risk. This will then entail that all staff working in a claims department will need to be compliant. It is therefore recommends that companies start getting training schedules in place to assist staff to complete the FIAS compliant examination.

A further recommendation would be to focus less on the letter of the word, but rather focus on creating a client-centric culture. Should a company embrace a client-centric culture, the principles of TCF will fall into place.

Communication and turnaround times were two of the biggest contributors that lead to the implementation of the current legislation. Companies will need to enhance communication methods in order to bring the customer up to date with progress throughout the claims cycle.

Over and above the recommendations made, the researcher further needs to emphasise the need that all staff within the intermediary model need to complete all FIAS exams in order to be compliant and on the same level as the direct companies. Claims negotiators and loss adjusters will now be in direct contact and supply advice to customers when confronted, which they are not allowed to do in the current environment.

\section{REFERENCES}

Bowman G (2012). A fair bit of confusion. [Online]. Available from: http://www.bowman. co.za/news-blog/blog/treating customers fairly in South Africa [Accessed: 2014-03-17] 
Exceed Consulting (2008). Five Key Elements for a successful implementation. [Online]. Available from: www.exceed-consult.com [Accessed:2014-04-21]

Feasibility (PTY) Ltd (2010).Treating Customers Fairly.[Online]. Available from: https:///www.fsb.co.za Treating Customers Fairly, pp. 8 - 10.[Accessed: 2014-04-21]

FIAS Act (2002). Government Gazette.[Online]. Available from: https://www.greengazette.co.za [Accessed: 2014-23-06]

FSB (2009). Discussion paper on Treating Customers Fairly roadmap. [Online]. Available from: www.fsb.co.za . [Accessed: 2014-05-22]

FSB (2009). Annual report roadmap.[Online]. Available from: www.fsb.co.za

[Accessed: 2014-05-22].

FSB (2014). The FSB Act (Act 97 of 1990). Chapter Three, Function of the Board. [Online].Available from www.fsb.co.za. [Accessed: 201501-23]

FSB (2010). Discussion paper on Treating Customers Fairly roadmap. [Online]. Available from: www.fsb.co.za [Accessed: 2014-05-22]

Financial Services Board Act (1990). List FSB. 2014. The FSB Act (Act 97 of 1990). Chapter Three, Function of the Board.[Online]. Available from: www.fsb.co.za [Accessed: 15-06-2014]

Green CA (2010). Qualitative Data. [Online]. Available from: http://www.researchgate.net/publication/258315317 [Accessed: 2014]

Hawkins P (2010). Treating Customers Fairly, A discussion paper for the financial service board, April 2010, Prepared by Feasibility (PTY) Ltd, Dr Penelope Hawkins, April 2010. [Online] Available from: www.google.co.za/search?tbm=bks\&hl=en\&q=hawkins $+\% 2 B t c f \# h l=e$ n\&q=hawkins $+2010+\% 2 B+$ tcf . [Accessed: 2014]

Jackson L (2011). Financial Services Board. [Online]. Available from: www.fsb.co.za/Departments/communications/Documents/TFCRoadM ap.pdf [Accessed: 2014]

KPMG (2012). TCF Discussion Document. [Online] Available from: www.fsb.co.za [Accessed: 2014-05-22]

Jackson L (2011). FSB - Treating Customers Fairly Long Term Ombudsman Annual Report, 2006:21

McMillan and Schumacher (2006) - Research in Education: Evidencebased Inquiry: James H McMillan and Sally Schumacher(2006) Edition 6, Pearson, Allyn and Bacon, ISBN 0205455301,9780205455300

Patton N (2002). Critical case sampling. [Online]. Available from: http://dissertation.laerd.com/purposive-sampling.php [Accessed 0607-2014]
RSA (2002). Financial Advisory and Intermediary Services Act 2002.[Online]. Available from: http://www.saflii.org/za/legis/consol_act/faaisa2002423/ [Accessed: 03-03-2014]

Sage Research Methods (2001). Benefits of Qualitative research. [Online]. Available from: http://srmo.sagepub.com/view/ quakitative research. [Accessed: 2015-04-22]

Taylor A (2012). PWC. Creating value for the Asset Management Industry. [Online]. Available from: https://www.pwc.co.za/en/assets/pdf/asset-management-serviceoffering-09-2012.pdf .[Accessed: 13-05-2014] 